\title{
Control of Nausea and Vomiting in Patients with Colorectal Cancer Receiving Chemotherapy with Moderate Emetic Risk
}

\author{
AKIO SUZUKI ${ }^{1}$, RYO KOBAYASHI ${ }^{1}$, HIRONORI FUJII ${ }^{1}$, HIROTOSHI IIHARA ${ }^{1}$, \\ TAKAO TAKAHASHI ${ }^{2}$, KAZUHIRO YOSHIDA $^{2}$ and YOSHINORI ITOH ${ }^{1}$ \\ ${ }^{1}$ Department of Pharmacy, Gifu University Hospital, Gifu, Japan; \\ ${ }^{2}$ Department of Surgical Oncology, Gifu University Graduate School of Medicine, Gifu, Japan
}

\begin{abstract}
Background: Chemotherapy with moderate emetic risk (MEC), including irinotecan-based and oxaliplatin-based chemotherapy regimens, are predominantly used for colorectal cancer chemotherapy. Chemotherapyinduced nausea and vomiting (CINV) remain unsatisfactorily controlled. Patients and Methods: The rates of prevalence of antiemetic medication and the control of CINV were investigated from medical records in patients with colorectal cancer who received the first cycle of irinotecan-based or oxaliplatin-based regimens. Risks for CINV were determined by multivariate logistic regression analysis. Results: A total of 179 patients received the first cycle of MEC regimens and the number of overall cycles was 2,176 during the study period from January 2013 to December 2015. Guidelineconsistent antiemetic medication was performed in most cases. The rate of no-CINV was nearly $90 \%$ during the overall period. Female sex and age under 50 years were significant risks for CINV. Comparison considering only the group aged 50 years or more indicated that the control of CINV was significantly worse in irinotecan-based regimens than in the oxaliplatin-based regimens. Conclusion: Female sex and age younger than 50 years were significant risks for CINV in patients receiving MEC for colorectal cancer. Moreover, the control of CINV was less sufficient for irinotecan-based than for oxaliplatin-based regimens.
\end{abstract}

Colorectal cancer (CRC) is one of common types of cancer in the world (1). Oxaliplatin-based and irinotecan-based

This article is freely accessible online.

Correspondence to: Akio Suzuki, Ph.D., Department of Pharmacy, Gifu University Hospital, 1-1 Yanagido, Gifu 501-1194, Japan. Email: akio@gifu-u.ac.jp

Key Words: Chemotherapy-induced nausea and vomiting, moderate emetic risk chemotherapy, colorectal cancer, irinotecan, oxaliplatin, risk analysis. regimens such as FOLFOX (leucovorin (LV)/5-fluorouracil (5-FU)/oxaliplatin), XELOX (oxaliplatin/capecitabine), FOLFIRI (LV/5-FU/irinotecan) are standard chemotherapies for CRC. It has been shown that these chemotherapies, when used in combination with or without monoclonal antibody raised against vascular endothelial growth factor or epidermal growth factor receptor, are effective for improvement of tumor response and prolongation of survival in patients with metastatic CRC (2-7).

Chemotherapy-induced nausea and vomiting (CINV) are still adverse reactions that impair a patient's quality of life (8). According to several clinical practice guidelines for prevention of CINV developed by the American Society of Clinical Oncology (ASCO) 2011 (9), National Comprehensive Cancer Network (NCCN) 2016 (10), and the Japanese Society of Clinical Oncology (JSCO) 2010 (11), oxaliplatin-based or irinotecan-based chemotherapy regimens are classified as being moderate emetic risk chemotherapy (MEC). These guidelines recommend using 5-hydroxytryptamine $3\left(5-\mathrm{HT}_{3}\right)$ receptor antagonist (day 1) in combination with dexamethasone (days 1-3) for prevention of CINV associated with MEC (12-14). The guidelines also indicated that the neurokinin $1\left(\mathrm{NK}_{1}\right)$ receptor antagonist, such as aprepitant, should be added to the above standard antiemetic medication when using an anticancer drug with relatively high emetic risk among MEC. However, the definition of relatively high emetic risk is vague since JSCO 2010 (11) indicated that aprepitant should be administered for patients receiving irinotecan, carboplatin, ifosfamide, and methotrexate, while NCCN 2016 (10) showed that aprepitant should be given selectively to patients with additional risk factors or those who experienced CINV in previous therapy using two-drug antiemetic medication.

It has been demonstrated that several factors, including female gender, age, no history of drinking, and history of hyperemesis gravidarum, are high risks for CINV $(11,15-$ 19). Additionally, the control rate of CINV by similar antiemetic medication is different among chemotherapy regimens of the same emetic risk category (20), and among 
cancer types (21). Therefore, the evaluation of risk factors for CINV with respect to the type of cancer is important in order to enhance the control of CINV.

In the present study, the rate of control and the risk for CINV were investigated in patients receiving MEC for CRC.

\section{Patients and Methods}

Patients. A total of 200 patients with CRC received 2,698 chemotherapy cycles at our outpatient chemotherapy setting during 3 years from January 2013 to December 2015. Among these patients, MEC was administered to 179 patients $(89.5 \%)$ and in 2,176 cycles $(80.7 \%)$. The present study was carried out in accordance with the guidelines for the care for human study adopted by the Ethics Committee of the Gifu Graduate School of Medicine, and notified by the Japanese Government (approval no. 26-153 of the Institutional Review Board).

Adherence to the JSCO guideline for the use of antiemetic drugs. The prevalence of guideline-consistent antiemetic medication and the control of CINV were retrospectively investigated from medical and pharmaceutical records for patients receiving the first cycle as well as the overall cycles of MEC regimens, including irinotecanbased and oxaliplatin-based chemotherapy regimens. The standard antiemetic medication was the combination of $5-\mathrm{HT}_{3}$ receptor antagonist such as granisetron ( $3 \mathrm{mg} /$ day, intravenously, on day 1) and dexamethasone $(9.9 \mathrm{mg} / \mathrm{day}$, intravenously, on day 1 and 4 $\mathrm{mg} /$ day, orally, on days 2 and 3 ).

Evaluation of the control of CINV. The control of CINV was evaluated by the rates of no significant (grade 2 and more) nausea, no vomiting, and non-significant nausea and vomiting during acute (within 24 hours), delayed (24-120 hours), and overall (0-120 hours) periods after chemotherapy.

Risk analysis for CINV in the overall period. Demographics of patients who received the first cycle of chemotherapy were compared between patients with CINV and those without CINV for the overall period. Subsequently, risk factors for CINV were determined by uni- and multivariate logistic regression analyses. Odds ratios (ORs) and 95\% confidence intervals (CIs) were determined. The cut-off age was determined by the Youden index method in the receiver operating characteristic curve (ROC) analysis, in which the Youden index was calculated as the maximum value of (sensitivity+specificity-1), according to methods described elsewhere $(22,23)$

Comparison of the control of CINV between irinotecan- and oxaliplatin-based chemotherapy regimens. The control rate of CINV was compared between patients receiving the first cycle of irinotecan-based chemotherapy and those with the first cycle of oxaliplatin-based chemotherapy. In order to avoid the influence of confounding factors for CINV; the control of CINV in the group of patients aged 50 years or more was compared by treatment.

Statistical analyses. Data were analyzed using IBM SPSS Statistics ver. 22 (IBM Japan Services Co., Ltd., Tokyo, Japan). Parametric variables were statistically compared by $t$-test, while nonparametric data were analyzed by Mann-Whitney $U$-test or Chi-square test. The rates of the control of CINV among three groups were statistically compared by Kruskal-Wallis test, followed by Scheffe's test. $p$-Values of less than 0.05 were considered statistically significant.

\section{Results}

Patient demographics. Table I shows the demographics of 179 patients with CRC who received the first cycle of MEC from January 2013 to December 2015 at our outpatient chemotherapy clinic. Among them, 126 patients $(70.4 \%)$ received oxaliplatin-based regimens and 53 patients $(29.6 \%)$ in first cycle, while, in overall cycles, oxaliplatin was also prescribed more frequently than irinotecan. The prevalence of guideline-consistent antiemetic premedication was $87.2 \%$ in the first cycle, while the rate was $81.3 \%$ overall cycles. Guideline-consistent antiemetic premedication was provided to over $80 \%$ of patients. About $90 \%$ of patients had no significant nausea or vomiting. Therefore, the high control rate of CINV is assumed to be due, at least in part, to a high rate of guideline-consistent antiemetic premedication.

Comparison of demographics between patients with CINV and those without CINV. As shown in Table II, females more frequently experienced CINV than did males $[60.9 \% \mathrm{vs}$. $35.9 \%$ of patients experiencing CINV; $p=0.039 ; 56$ out of 70 females $(80 \%)$ vs. 9 out of 100 males $(9 \%)]$. The percentage of patients under 50 years old who experienced CINV was also significantly higher $(30.4 \%$ vs. 9.6\%; $p=0.013)$, although no significant difference in average age was observed between the two groups. The adherence to the antiemetic guideline was not different between the two groups $(91.3 \%$ vs. $85.9 \% ; p=0.702)$. Moreover, no significant differences in other characteristics of patients existed between the two groups.

Risk analysis for CINV. As shown in Table III, multivariate analysis showed that female gender $(\mathrm{OR}=2.870,95 \%$ $\mathrm{CI}=1.139-7.228 ; p=0.025)$ and age under 50 years $(\mathrm{OR}=4.277$; 95\% CI=1.472-12.424; $p=0.008$ ) were significant risk factors for CINV in patients receiving their first cycle of chemotherapy.

It is noteworthy that the rates of no significant nausea or no significant nausea/no vomiting significantly decreased almost linearly as the number of risk factors increased (Figure 1). On the other hand, the rate of no vomiting was lowered only when both the two risk factors were present.

Comparison of the rate of CINV between irinotecan-based and oxaliplatin-based regimens. In order to determine the difference in the control of CINV between irinotecan-based and oxaliplatin-based regimens, the demographics of patients who received the first cycle of chemotherapy were compared. As shown in Table IV, there were no significant 
Table I. Demographics of patients and control of chemotherapy-induced nausea and vomiting in patients with colorectal cancer receiving chemotherapy with moderate emetic risk.

\begin{tabular}{|c|c|c|c|c|}
\hline Gender (female/male), $n$ & \multicolumn{4}{|c|}{$70 / 109$} \\
\hline Age (range), years & \multicolumn{4}{|c|}{$63.4(38-85)$} \\
\hline Height, $\mathrm{cm}$ & \multicolumn{4}{|c|}{$160.8 \pm 15.0$} \\
\hline Body weight, kg & \multicolumn{4}{|c|}{$58.3 \pm 12.6$} \\
\hline Body surface area, m2 & \multicolumn{4}{|c|}{$1.60 \pm 0.23$} \\
\hline Serum creatinine, $\mathrm{mg} / \mathrm{dl}$ & \multicolumn{4}{|c|}{$0.68 \pm 0.26$} \\
\hline \multirow[t]{2}{*}{ Chemotherapy regimen } & \multicolumn{2}{|c|}{$\begin{array}{l}\text { First cycle } \\
(\mathrm{N}=179)\end{array}$} & \multicolumn{2}{|c|}{$\begin{array}{c}\text { Overall } \\
(\mathrm{N}=2179)\end{array}$} \\
\hline & $\mathrm{N}$ & $\%$ & $\mathrm{~N}$ & $\%$ \\
\hline Oxalipatin-based & 126 & 70.4 & 1,243 & 57.1 \\
\hline Modified FOLFOX6 & 47 & 26.3 & 682 & 31.8 \\
\hline Capecitabine/oxaliplatin & 55 & 30.7 & 435 & 20.0 \\
\hline TS-1/oxaliplatin & 24 & 13.4 & 116 & 5.3 \\
\hline Irinotecan-based & 53 & 29.6 & 933 & 42.9 \\
\hline FOLFIRI & 42 & 23.5 & 779 & 35.8 \\
\hline Irinotecan & 6 & 3.4 & 42 & 1.9 \\
\hline TS-1/irinotecan & 5 & 2.8 & 94 & 4.3 \\
\hline Capecitabine/irinotecan & 0 & 0 & 18 & 0.8 \\
\hline \multicolumn{5}{|c|}{ Prevalence of antiemetic medication } \\
\hline Acute & 179 & 100 & 2,166 & 99.5 \\
\hline Delayed & 156 & 87.2 & 1,771 & 81.4 \\
\hline Overall & 156 & 87.2 & 1,768 & 81.3 \\
\hline \multicolumn{5}{|l|}{ Control of nausea } \\
\hline Acute & 167 & 93.3 & 2,072 & 95.2 \\
\hline Delayed & 158 & 88.2 & 2,017 & 92.7 \\
\hline Overall & 157 & 87.7 & 2,002 & 92.0 \\
\hline \multicolumn{5}{|l|}{ Control of vomiting } \\
\hline Acute & 174 & 97.2 & 2,129 & 97.8 \\
\hline Delayed & 173 & 96.6 & 2,125 & 97.7 \\
\hline Overall & 172 & 96.1 & 2,100 & 96.5 \\
\hline \multicolumn{5}{|c|}{ Control of nausea and vomiting } \\
\hline Acute & 166 & 92.7 & 2,062 & 94.8 \\
\hline Delayed & 158 & 88.3 & 2,003 & 92.0 \\
\hline O verall & 156 & 87.2 & 1,981 & 91.0 \\
\hline
\end{tabular}

Data are mean \pm S.D, or absolute numbers, with percentage.

differences in patients' demographics except for age and under 50-year-old patients. Patients receiving irinotecanbased regimens were significantly older than those who received oxaliplatin-based regimens (67.7 years vs. 61.6 years; $p<0.01$ ). There were significantly fewer patients aged under 50 years receiving irinotecan-based regimens.

Subsequently, the rate of control of CINV was compared between irinotecan-based regimens and oxaliplatin-based regimens. As shown in Table V, no significant differences existed between the two groups before considering age. Since age was found to be a significant risk for CINV, the control of CINV was compared again considering data obtained from patients $\geq 50$ years old. Considering this age

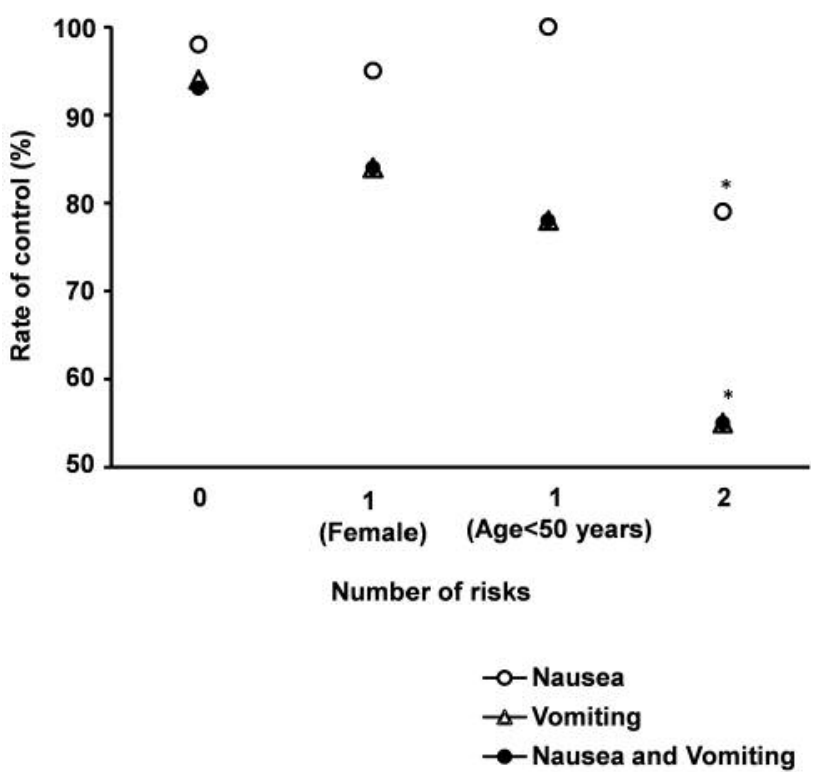

Figure 1. Relationship between the number of risk factors and the rates of no significant nausea, no vomiting and no significant nausea/no vomiting. ${ }^{*} p<0.05$ vs. respective rate without any risk factor by Kruskal-Wallis test, followed by Scheffe's test.

Table II. Comparision of demographics of colorectal cancer patients receiving the first cycleof moderate emetic risk chemotherapy between patients with and without chemotherapy induced nausea and vomiting $(C I N V)$.

\begin{tabular}{lccc}
\hline & $\begin{array}{c}\text { Without CINV } \\
(\mathrm{N}=156)\end{array}$ & $\begin{array}{c}\text { With } \\
\text { CINV (N=23) }\end{array}$ & $p$-Value \\
\hline Gender (female), n (\%) & $56(35.9 \%)$ & $14(60.9 \%)$ & $0.039^{\mathrm{a}}$ \\
Age (range), years & $63.8(38-85)$ & $60.3(38-84)$ & $0.287^{\mathrm{b}}$ \\
Aged under 50 years, n (\%) & $15 / 141(9.6 \%)$ & $7 / 16(30.4 \%)$ & $0.013^{\mathrm{a}}$ \\
Chemotherapy regimen, n (\%) & & & \\
$\quad$ Oxaliplatin-based & $112(71.8 \%)$ & $15(65.2 \%)$ & $0.687^{\mathrm{a}}$ \\
$\quad$ Irinotecan-based & $44(28.2 \%)$ & $8(34.8 \%)$ & \\
Height, cm & $161.1 \pm 15.8$ & $159.2 \pm 8.3$ & $0.578^{\mathrm{c}}$ \\
$\begin{array}{l}\text { Body weight, g } \\
\text { Body surface area, m }{ }^{2}\end{array}$ & $58.7 \pm 12.4$ & $55.6 \pm 13.7$ & $0.267^{\mathrm{c}}$ \\
Serum creatinine, mg/dl & $1.61 \pm 0.23$ & $1.56 \pm 0.21$ & $0.338^{\mathrm{c}}$ \\
Adherence to antiemetic & $0.71 \pm 0.22$ & $0.70 \pm 0.25$ & $0.818^{\mathrm{c}}$ \\
guideline, n $(\%)$ & $134(85.9 \%)$ & $21(91.3 \%)$ & $0.702^{\mathrm{a}}$ \\
& & & \\
\hline
\end{tabular}

${ }^{a}$ Chi-squared-test, ${ }^{\mathrm{b}}$ Mann-Whitney $U$-test, ${ }^{\mathrm{c}} t$-test. Data are the mean \pm S.D, or absolute number, with percentage.

group alone, the rate of no significant nausea/no vomiting during the acute period was significantly lower in those treated with irinotecan-based regimens than in those treated with oxaliplatin-based regimens $(86.3 \%$ vs. 97.2\%; $p=0.023)$. The rate of no significant nausea during the acute 
Table III. Univariate and multivariate logistic regression analysis for the risk of chemotherapy-induced nausea and vomiting in patients with colorectal cancer who received moderate emetic risk chemotherapy in the outpatient chemotherapy setting.

\begin{tabular}{|c|c|c|c|c|c|c|}
\hline & \multicolumn{3}{|c|}{ Univariate analysis } & \multicolumn{3}{|c|}{ Multivariate analysis } \\
\hline & OR & $(95 \% \mathrm{CI})$ & $p$-Value & OR & $(95 \% \mathrm{CI})$ & $p$-Value \\
\hline Female & 2.778 & $(1.130-6.826)$ & 0.026 & 2.870 & $(1.139-7.228)$ & 0.025 \\
\hline Age under 50 years & 4.113 & $(1.460-11.583)$ & 0.007 & 4.227 & $(1.427-12.424)$ & 0.008 \\
\hline
\end{tabular}

OR: Odds ratio; $\mathrm{CI}$ : confidence interval.

period $(88.2 \%$ vs. $97.2 \% ; p=0.059)$ and the rate of no vomiting during the overall period $(92.2 \%$ vs. $99.1 \%$; $p=0.069$ ) were also lower, although not significantly, in irinotecan-based regimens than in oxaliplatin-based regimens.

\section{Discussion}

In the present study, we surveyed the rate of control of CINV in 179 patients who received their first cycle of MEC and a total of 2,176 cycles in our outpatient cancer chemotherapy clinic. Adverse drug reactions were monitored in all patients by health professionals, including pharmacists and nurses. In addition, we checked the prescription for antiemetic medication and promoted appropriate use of antiemetic drugs.

As a consequence, the prevalence of guideline-consistent antiemetic medication during the overall period was sufficiently high, at $87 \%$ and $91 \%$ in the first cycle of chemotherapy and overall cycles of chemotherapy, respectively. Under such conditions, the rate of CINV control was $88 \%$ for no significant nausea, $96 \%$ for no vomiting, and $87 \%$ for no significant nausea/no vomiting during the overall period of the first cycle of chemotherapy. The rates were even higher in overall cycles of chemotherapy. Aridome et al. reported in patients with CRC who received standard antiemetic medication that the rate of complete response (CR; no vomiting and no rescue treatment) was $80 \%$ during the overall period (24). Hesketh et al. also reported in patients receiving irinotecan-based MEC regimens that the rate of CR was $77 \%$ during the overall period (25). It seems likely that the rate of no significant nausea/no vomiting in the present study is similar to the rate of CR. Therefore, our present data on the control of CINV in patients with CRC who received MEC were generally consistent with data reported previously.

Several investigators have reported on the risk factors for CINV. Sekine et al. reported in 1,549 patients receiving high emetic risk of MEC that females were more likely to experience failure in CR than males (26). Hilarius et al. also showed in 225 patients receiving high emetic risk or MEC that the incidence rates of acute and delayed nausea
Table IV. Comparision of patient demographics between irinotecanbased and oxaliplatin-based chemotherapy groups.

\begin{tabular}{lccc}
\hline & $\begin{array}{c}\text { Irinotecan-based } \\
(\mathrm{N}=52)\end{array}$ & $\begin{array}{c}\text { Oxaliplatin-based } \\
(\mathrm{N}=127)\end{array}$ & $p$-Value \\
\hline Gender (female), $\mathrm{n}$ & 15 & 55 & $0.103^{\mathrm{a}}$ \\
Age, range, years & $67.7(47-85)$ & $61.6(38-84)$ & $<0.01^{\mathrm{b}}$ \\
Age under 50 years, $\mathrm{n}$ & 1 & 21 & $0.014^{\mathrm{a}}$ \\
Height, cm & $161.3 \pm 8.4$ & $160.6 \pm 17.1$ & $0.765^{\mathrm{c}}$ \\
Body weight, $\mathrm{kg}$ & $59.0 \pm 11.2$ & $58.0 \pm 13.1$ & $0.640 \mathrm{c}$ \\
Body surface area, $\mathrm{m}^{2}$ & $1.62 \pm 0.18$ & $1.59 \pm 0.25$ & $0.544^{\mathrm{c}}$ \\
Serum creatinine, $\mathrm{mg} / \mathrm{dl}$ & $0.73 \pm 0.26$ & $0.66 \pm 0.26$ & $0.127^{\mathrm{c}}$ \\
\hline
\end{tabular}

${ }^{\mathrm{a} C h i}$-squared-test, ${ }^{\mathrm{b}}$ Mann-Whitney $U$-test, ${ }^{\mathrm{c}} t$-test. Data are mean \pm S.D, or absolute number with percentage.

and vomiting were significantly higher in females than males (18). On the other hand, it has been reported that younger age is one of the risks for the loss of emetic control (15-16, 18, 26-27). However, the cut-off value of age that influences the control of CINV remains unclear: poor control of CINV was reportedly associated with age under 55 years $(19,26)$, age under 65 years $(17,18)$, and age under 40 years (15). We reported very recently that in 608 patients receiving the first cycle of chemotherapy with any emetic risk, age under 50 years was significantly associated with high risk of CINV (OR=5.803, 95\% $\mathrm{CI}=2.667-12.63 ; p<0.001)(21)$.

In the present study, multivariate analysis also showed that female gender was a significant risk for CINV (OR: 2.870; 95\% CI, 1.139-7.228; $p=0.025)$. Although age was not significantly different between patients who had CINV and those without CINV (60.3 years vs. 63.8 years; $p=0.287$ ), the percentage of patients under 50 years old was significantly higher in patients with CINV than in those without CINV (30.4\% vs. 9.6\%; $p=0.013$ ). The cut-off age was estimated from the Youden index of the ROC curve plotted by sensitivity versus 1 -specificity, and the value was predicted to be 48.5 years. Thus, in the present study, the cut-off age was set to 50 years. The present cut-off age was consistent 
Table V. Comparision of the incidence of chemotherapy-induced nausea and vomiting (CINV) between irinotecan-based and oxaliplatin-based chemotherapy for the whole cohort of patients with colorectal cancer and those aged 50 years or more.

\begin{tabular}{|c|c|c|c|c|c|c|}
\hline \multirow[b]{2}{*}{ CINV } & \multicolumn{3}{|c|}{ Whole cohort, \% } & \multicolumn{3}{|c|}{ Age $\geq 50$ years, $\%$} \\
\hline & Irrinotecan $(\mathrm{N}=52)$ & Oxaliplatin $(\mathrm{N}=127)$ & $p$-Value & Irrinotecan $(\mathrm{N}=51)$ & Oxaliplatin $(\mathrm{N}=106)$ & $p$-Value \\
\hline \multicolumn{7}{|l|}{ No nausea } \\
\hline Acute & 88.5 & 95.3 & 0.185 & 88.2 & 97.2 & 0.059 \\
\hline Delayed & 86.5 & 89.0 & 0.838 & 86.3 & 93.4 & 0.243 \\
\hline Overall & 86.5 & 88.2 & 0.956 & 86.3 & 92.5 & 0.346 \\
\hline \multicolumn{7}{|c|}{ No vomiting } \\
\hline Acute & 94.2 & 98.4 & 0.295 & 94.1 & 99.1 & 0.194 \\
\hline Delayed & 94.2 & 97.6 & 0.489 & 94.1 & 99.1 & 0.194 \\
\hline Overall & 92.3 & 97.6 & 0.213 & 92.2 & 99.1 & 0.069 \\
\hline \multicolumn{7}{|c|}{ No nausea and vomiting } \\
\hline Acute & 86.5 & 95.3 & 0.084 & 86.3 & 97.2 & 0.023 \\
\hline Delayed & 86.5 & 89.0 & 0.838 & 86.3 & 93.4 & 0.243 \\
\hline Overall & 84.6 & 88.2 & 0.687 & 84.3 & 92.5 & 0.195 \\
\hline \multicolumn{7}{|c|}{ Antiemetic medication prevalence } \\
\hline Acute & 100 & 100 & 1 & 100 & 100 & 1 \\
\hline Delayed & 78.8 & 90.6 & 0.06 & 78.4 & 89.6 & 0.10 \\
\hline Overall & 78.8 & 90.6 & 0.06 & 78.4 & 89.6 & 0.10 \\
\hline
\end{tabular}

with that reported previously (21) and that reported by Blanke et al. (28), who showed that patients with CRC younger than 50 years are at a high risk of grade 3 or more nausea $(\mathrm{OR}=1.38,95 \% \mathrm{CI}=1.07-1.78 ; p=0.01)$ and vomiting $(\mathrm{OR}=1.33,95 \% \mathrm{CI}=1.00-1.77, p=0.05)$.

It was notable that the rate of no significant nausea or no significant nausea/no vomiting decreased almost linearly as the number of risk factors (female and age younger than 50 years) increased. However, the control of vomiting was reduced only when both risks were present.

On the other hand, we compared the control of CINV between irinotecan-based and oxaliplatin-based regimens. Patients receiving irinotecan-based regimens were significantly older than those receiving oxaliplatin-based regimens $(67.7$ years $v s .61 .6$ years; $p<0.01)$. Since age was found to be a significant risk for CINV, the control of CINV was compared considering only data obtained from patients $\geq 50$ years old. As a result, the rate of no significant nausea/no vomiting during acute period was significantly lower in irinotecan-based regimens than in oxaliplatin-based regimens $(86.3 \%$ vs. $97.2 \% ; p=0.023)$.

The clinical practice guidelines for prevention of CINV recommend addition of $\mathrm{NK}_{1}$ receptor antagonist to the twodrug antiemetic medication of $5-\mathrm{HT}_{3}$ receptor antagonist and dexamethasone, when using drugs relatively high emetic risk among MEC (11-14). NCCN 2016 indicated that aprepitant should be prescribed to select patients with additional risk factors or those who experienced CINV in previous therapy using two-drug regimen (10). Taken together, our present findings suggest that three-drug antiemetic medication, including aprepitant, 5- $\mathrm{HT}_{3}$ receptor antagonist and dexamethasone on day 1 and aprepitant and dexamethasone on days 2 and 3 , should be administered to female patients under 50 years old receiving MEC for CRC.

There are several limitations in the present study. Firstly, the present study was a non-randomized single-center study. Secondly, only a small number of patients experienced CINV. Thirdly, data on CR, one of most common indices of the control of CINV, were not included because it was difficult to obtain data on the rescue treatment.

In conclusion, the control of CINV was investigated in 179 patients with $\mathrm{CRC}$ receiving the first cycle of MEC and the number of overall cycles was 2,176 in our outpatient cancer chemotherapy clinic. The guideline-consistent twodrug antiemetic medication of 5-HT3 receptor antagonist and dexamethasone was carried out in most cycles. Although the control of CINV was generally satisfactory, CINV was poorly controlled in patients younger than 50 years and in females. In addition, the rate of CINV control was significantly lower in the irinotecan-based regimens than in the oxaliplatin-based regimens.

\section{Conflicts of Interest}

The Authors declare that they have no conflict of interest in regard to this study.

\section{Source of Funding}

None declared. 


\section{References}

1 Ferlay J, Shin HR, Bray F, Forman D, Mathers C and Parkin DM: Estimates of worldwide burden of cancer in 2008: GLOBOCAN Int J Cancer 127: 2893-2917, 2008.

2 Andre T, Boni C, Navarro M, Tabernero J, Hickish T, Topham C, Bonetti A, Clingan P, Bridgewater J, Rivera $\mathrm{F}$ and de Gramont A: Improved overall survival with oxaliplatin, fluorouracil and leucovorin as adjuvant treatment in stage II or III colon cancer in the MOSAIC trial. J Clin Oncol 27: 31093116, 2009.

3 Cassidy J, Tabernero J, Twelves C, Brunet R, Butts C, Conroy T, Debraud F, Figer A, Grossmann J, Sawada N, Schoffski P, Sobrero A, Van Cutsem E and Diaz-Rubio E: XELOX (capecitabine plus oxaliplatin): active first-line therapy for patients with metastatic colorectal cancer. J Clin Oncol 22: 2084-2091, 2004.

4 de Gramont A, Figer A, Seymour M, Homerin M, Hmissi A, Cassidy J, Boni C, Cortes-Funes H, Cervantes A, Freyer G; Papamichael D, Le Bail N, Louvet C, Hendler D, de Braud F, Wilson C, Morvan F and Bonetti A: Leucovorin and fluorouracil with or without oxaliplatin as first-line treatment in advanced colorectal cancer. J Clin Oncol 18: 2938-2947, 2000.

5 Haller DG, Tabernero J, Maroun J, de Braud F; Price T, Van Cutsem E, Hill M, Gilberg F, Rittweger K and Schmoll HJ: Capecitabine plus oxaliplatin compared with fluorouracil and folinic acid as adjuvant therapy for stage III colon cancer. J Clin Oncol 29: 1465-1471, 2011.

6 Hurwitz H, Fehrenbacher L, Novotny W, Cartwright T, Hainsworth J, Heim W, Berlin J, Baron A, Griffing S, Holmgren E, Ferrara N, Fyfe G, Rogers B, Ross R and Kabbinavar F: Bevacizumab plus irinotecan, fluorouracil and leucovorin for metastatic colorectal cancer. New Engl J Med 350: 2335-2342, 2004.

7 Saltz LB, Clarke S, Diaz-Rubio E, Scheithauer W, Figer A, Wong R, Koski S, Lichinitser M, Yang TS, Rivera F, Couture F, Sirzen F and Cassidy J: Bevacizumab in combination with oxaliplatin-based chemotherapy as first-line therapy in metastatic colorectal cancer: a randomized phase III study. J Clin Oncol 26: 2013-2019.

8 de Boer-Dennert M, de Wit R, Schmitz PI, Djontono J, Beurden $\mathrm{V}$, Stoter G and Verweij J: Patient perceptions of the side-effects of chemotherapy: the influence of 5HT3 antagonists. Br J Cancer 76: 1055-1061, 1997.

9 Basch E; Prestrud AA, Hesketh PJ, Kris MG, Feyer PC, Somerfield MR, Chesney M, Clark-Snow RA, Flaherty AM, Freundlich B, Morrow G, Rao KV, Schwartz RN, Lyman GH and American Society of Clinical O: Antiemetics: American Society of Clinical Oncology clinical practice guideline update. J Clin Oncol 29: 4189-4198, 2011.

10 National Comprehensive Cancer Network (NCCN). Clinical Practice Guidelines in Oncology (NCCN Guidelines $\left.{ }^{\circledR}\right)$. Antiemesis Version 1.2016: http://www.ncen.org/professionals/ physician_gls/pdf/antiemesis.pdf

11 Takeuchi H, Saeki T, Aiba K, Tamura K, Aogi K, Eguchi K, Okita K, Kagami Y, Tanaka R, Nakagawa K, Fujii H, Boku N, Wada M, Akechi T, Udagawa Y, Okawa Y, Onozawa Y, Sasaki H, Shima Y, Shimoyama N, Takeda M, Nishidate T, Yamamoto A, Ikeda T and Hirata K: Japanese Society of Clinical Oncology clinical practice guidelines 2010 for antiemesis in oncology: executive summary. International J Clin Oncol 21: 1-12, 2016.
12 Herrstedt J, Aapro MS, Roila F, Kataja VV and Force EGT: ESMO Minimum Clinical Recommendations for prophylaxis of chemotherapy-induced nausea and vomiting (NV). Ann Oncology 16(Suppl 1): i77-79, 2005.

13 Hesketh PJ, Bohlke K, Lyman GH, Basch E, Chesney M, ClarkSnow RA, Danso MA, Jordan K, Somerfield MR, Kris MG and American Society of Clinical O: Antiemetics: American Society of Clinical Oncology Focused Guideline Update. J Clin Oncol 34: 381-386, 2016.

14 Roila F, Herrstedt J, Aapro M, Gralla RJ, Einhorn LH, Ballatori E, Bria E, Clark-Snow RA, Espersen BT, Feyer P, Grunberg SM, Hesketh PJ, Jordan K, Kris MG, Maranzano E, Molassiotis A, Morrow G, Olver I, Rapoport BL, Rittenberg C, Saito M, Tonato M, Warr D and Group EMGW: Guideline update for MASCC and ESMO in the prevention of chemotherapy- and radiotherapy-induced nausea and vomiting: results of the Perugia consensus conference. Ann Oncol 21(Suppl 5): v232-243, 2010.

15 Booth CM, Clemons M, Dranitsaris G, Joy A, Young S, Callaghan W, Trudeau M and Petrella T: Chemotherapy-induced nausea and vomiting in breast cancer patients: a prospective observational study. J Support Oncol 5: 374-380, 2007.

16 Fraunholz I, Grau K, Weiss C and Rodel C: Patient- and treatment-related risk factors for nausea and emesis during concurrent chemoradiotherapy. Strahlenther Onkol 187: 1-6, 2011.

17 Hesketh PJ, Aapro M, Street JC and Carides AD: Evaluation of risk factors predictive of nausea and vomiting with current standard-of-care antiemetic treatment: analysis of two phase III trials of aprepitant in patients receiving cisplatin-based chemotherapy. Support Care Cancer 18: 1171-1177, 2010.

18 Hilarius DL, Kloeg PH, van der Wall E, van den Heuvel JJ, Gundy CM and Aaronson NK: Chemotherapy-induced nausea and vomiting in daily clinical practice: a community hospitalbased study. Support Care Cancer 20: 107-117, 2012.

19 Warr DG, Street JC and Carides AD: Evaluation of risk factors predictive of nausea and vomiting with current standard-of-care antiemetic treatment: analysis of phase 3 trial of aprepitant in patients receiving adriamycin-cyclophosphamide-based chemotherapy. Support Care Cancer 19: 807-813, 2011.

20 Aoki S, Iihara H, Nishigaki M, Imanishi Y, Yamauchi K, Ishihara $\mathrm{M}$, Kitaichi $\mathrm{K}$ and Itoh $\mathrm{Y}$ : Difference in the emetic control among highly emetogenic chemotherapy regimens: Implementation for appropriate use of aprepitant. Mol Clin Oncology 1: 41-46, 2013.

21 Iihara H, Fujii H, Yoshimi C, Yamada M, Suzuki A, Matsuhashi $\mathrm{N}$, Takahashi T, Yoshida K and Itoh Y: Control of chemotherapyinduced nausea in patients receiving outpatient cancer chemotherapy. Int J Clin Oncol 21: 409-418, 2016.

22 Akobeng AK: Understanding diagnostic tests 3: Receiver operating characteristic curves. Acta paediatrica 96: 644-647, 2007.

23 Hajian-Tilaki K: Receiver operating characteristic (roc) curve analysis for medical diagnostic test evaluation. Caspian J Intern Med 4: 627-635, 2013.

24 Aridome K, Mori SI, Baba K, Yanagi M, Hamanoue M, Miyazono F, Tokuda K, Imamura H, Ogura Y, Kaneko K, Kijima F, Maemura K, Ishigami $S$ and Natsugoe S: A phase II, randomized study of aprepitant in the prevention of chemotherapy-induced nausea and vomiting associated with moderately emetogenic chemotherapies in colorectal cancer patients. Mol Clin Oncology 4: 393-398, 2016. 
25 Hesketh PJ, Bosnjak SM, Nikolic V and Rapoport B: Incidence of delayed nausea and vomiting in patients with colorectal cancer receiving irinotecan-based chemotherapy. Support care cancer 19: 2063-2066, 2011

26 Sekine I, Segawa Y, Kubota K and Saeki T: Risk factors of chemotherapy-induced nausea and vomiting: index for personalized antiemetic prophylaxis. Cancer Sci 104: 711-717, 2013.

27 Tamura K, Aiba K, Saeki T, Nakanishi Y, Kamura T, Baba H, Yoshida K, Yamamoto N, Kitagawa Y, Maehara Y, Shimokawa M, Hirata $\mathrm{K}$, Kitajima $\mathbf{M}$ and Japan CSGo: Testing the effectiveness of antiemetic guidelines: results of a prospective registry by the CINV Study Group of Japan. Int J Clin Oncol 20 : $855-865,2015$.
28 Blanke CD, Bot BM, Thomas DM, Bleyer A, Kohne CH, Seymour MT, de Gramont A, Goldberg RM and Sargent DJ: Impact of young age on treatment efficacy and safety in advanced colorectal cancer: a pooled analysis of patients from nine first-line phase III chemotherapy trials. J Clin Oncol 29: 2781-2786, 2011.
Received August 10, 2016

Revised September 29, 2016 Accepted September 30, 2016 